\title{
GRI-rapport 2004:5
}

\section{On Time, Space, and Action Nets}

\section{Barbara Czarniawska}

Paper prepared for the International Conference on Spacing and Timing: Rethinking Globalization and Standardization, Palermo, Italy, November 1-3, 2001. The author wishes to thank Karin Knorr Cetina, an anonymous reviewer and members of the research program "Organizing in Action Nets" at Gothenburg Research Institute for their comments. To appear in Organization.

GRI (Gothenburg Research Institute), School of Economics and Commercial Law at Göteborg University, Box 600, SE 40530 Göteborg, Phone: +46 77310 00, Fax: +46 77356 19, e-mail: firstname.surname@gri.gu.se Homepage: www.handels.gu.se/gri 



\title{
ON TIME, SPACE, AND ACTION NETS
}

\begin{abstract}
Laboratory studies, especially those by Latour and Woolgar (1979/1986) and Knorr Cetina (1981) proved to be an invaluable source of inspiration for students of organizing. Laboratories, however, are mostly reminiscent of simple factories, an organization form that is no longer central in today's world of work organizations. Two aspects of factory-like organizing are problematized in this paper: the dominance of chronological time and the existence of centers of calculation. Complementing these with kairotic time and dispersed calculation will bring the two kinds of studies even closer. Such a rapprochement will allow for adjusting the methodological approaches in studies of organization in a way similar to that dominant in SST (studies of science and technology) research. Two such changes are suggested: the reversal of the time perspective (action nets instead of organizations as study objects) and mobile ethnologies, facilitating study of the ways of life and work of people who move around a great deal.
\end{abstract}





\section{ON TIME, SPACE, AND ACTION NETS}

The topics I wish to address in this paper are the contest between chronological and kairotic time in contemporary organizing, and the emergence of dispersed calculation (as opposed to "calculation centers" postulated by Callon, 1998, and Latour, 1999a). Constant time measurement and centers of calculation exist mostly as sediments of bygone institutional orders, and they play central roles only in laboratory-like, or factory-like aspects of organizing. In the center of contemporary organizing are kairotic time and dispersed calculation. But if students of organizing are to take this into account, their approach to their study objects must be changed, and studies of science and technology have much to offer here.

In the first place, the time perspective must be changed: "organization" needs to be seen as a type of a final product, and not as a starting point. Secondly, traditional ethnography, bounded as it is to one place, misses the mobility inherent in contemporary organizing. Focusing on action nets and mobile ethnology are possible ways of escaping the iron cage of research tradition.

\section{Chronological and kairotic time}

My study of the introduction of sub-municipal committees in Sweden (CzarniawskaJoerges, 1988) ${ }^{1}$ started with a semi-structured interview beginning with the following innocent question: "Can you tell me something about the history of the reform? When did it all begin, in your view?" I received the following types of answers:

- in ancient Greece,

- in Viking villages,

- in the 1940s,

- in 1962 (the year of a centralizing administrative reform)

- in 1971 (the middle of the centralizing reform)

- in 1977

- in 1979

- in 1985 (seriously).

\footnotetext{
${ }^{1}$ It was an important reform, as local governments are crucial to Swedish public administration, in contrast to most European countries where public administration equals state administration.
} 
I was somewhat taken aback by the variety of responses, chose a middle way (early beginnings in the mid-1970s, culmination at present), and comforted myself that, as everybody knows, respondents' memories are never reliable. But my unease with this explanation returned when a colleague told me that, in a similar study conducted later, he asked people about the origins of a reorganization that was taking place, and was informed that it started with the participation of several persons in a conference organized in Brussels. Interested in this conference, my colleague tried to locate it in existing documents, and came to the conclusion that, to his and EU-people's knowledge, no such conference ever took place. He confronted his interlocutors with this piece of news and heard in response, "Well, perhaps it was not in Brussels, but it was somewhere, and around that time". Later on I realized that, looking as we both were for "the beginning", we failed to notice that it is the ending that chooses its beginning, not the other way around. Different endings require different beginnings - this is how the construction of a story proceeds (on ending-embedded stories, see Mandler, 1984).

A seminar on "Historical Fulfillment" by Hayden White (2000) helped me to make some sense of these confusing experiences. White claims that it is impossible to speak about history as the study object for the discipline of history: the latter's proper subject should be historiographies, different ways of writing history. The traditional discipline of history dedicates almost no attention to the form this writing takes thus a title of one of White's books, The Content of the Form (1987). Studying western historiography, he came to the conclusion that it underwent a dramatic change of paradigm: from chronological to kairotic time ordering.

Chronos (chrónos) was the Greek god (or at least impersonation) of time, while Kairos was the god of right time, of proper time. Kairós in Greek means "time, place, circumstances of a subject" (Lanham 1991). While Chronos measures time in mechanical intervals, Kairos jumps and slows down, omits long periods and remains in others. According to White, the switch from chronological to kairotic time is best symbolized by the conversion of Saul: time started anew for him after he became Paul. In European history, one can trace the change from "annals" to "chronicles" and to a "proper history". White quotes the "History of France" by Richerus of Rheims (ca 998) as being halfway between a purely chronological account (such as 
annals) and a kairotic narrative ("proper history"). It has a central subject, a geographical center, a social center, and a beginning in time.

But the work fails as proper history, at least according to the opinion of later commentators, by virtue of two considerations. First, the order of the discourse follows the order of chronology; it presents events in the order of their occurrence and cannot, therefore, offer the kind of meaning that a narratologically governed account can be said to provide. Second, probably owing to the "annalistic" order of discourse, the account does not so much conclude as simply terminate .... (1987, p.17).

I was struck by the similarity of these transformations in historiography with the transformation of events into a story (history) at the City Office in Stockholm during my study (Czarniawska, 2003). The main event attracting everybody's attention, time and effort at that time was the district reform (a variation on sub-municipal reform which Stockholm decided to introduce 10 years later than most other municipalities). I could see it happening; I also interviewed the project leader, and I was later given a historical perspective on the event. Here is a short excerpt from my field notes.

One Day at a City Office (shadowing of a Manager)

08.00 Moving into the new office. People move up and down the corridor, carry boxes, arrange the coffee room.

08.30 Conversation (about district reform) with the researcher in a car on the way to the training $\&$ development center

09.00 Coffee chat (an emergency stop in the subway system prevented most of the course participants from arriving on time)

09.45 Introduction to the course (dedicated to the presentation of the consequences of district reform to the City Office)

10.30 Return to the office. A tour around new offices, chats about the reform.

10.45 Manager works at his computer

11.10 A ventilation specialist comes in (new offices have faulty ventilation) ...and so on....

Not much of a story, right? And yet it is a chronologically structured account of how the reform proceeds. In many contexts such a logbook might be an accepted form of 
history - probably, in settings organized around machines, such as boats, planes, laboratories. But not in organizations I visited, where technologies were soft and often invisible (that is, forgotten or not recognized as technologies). The project leader, as it turned out, used a MasterPlan program (another chronological device) to run her project, but she did not tell the story according to the MasterPlan. Her account resembled a chronicle: there were characters, a context, there was a beginning - but the end was only the end of the account. The plot and the point were still missing. The plot and the point were, however, very visible in the following interviews that commented on the district reform (for a fuller account, see Czarniawska, 2003). There, Chronos almost completely yielded to Kairos.

In organizations I have visited, chronological accounts were raw material for kairotically-organized narratives, just as they were for me in my research. Most likely, kairotic time cannot be directly experienced, not even in laboratories: it must be made. John Law (1994) pointed out that nothing ever happens right where and when the researcher is observing. All important events happen at some other time, in some other place. While in the beginning the researchers tend to panic and try to chase "the action", in time they learn that "important events" become such in accounts. Nobody is aware that an important event is happening when it takes place, although in most cases people are aware of the time of the day, the day of the month etc. But they are not aware of the importance of the event; events must be made important (or not). Chronology organizes the present (extended to the immediate future). The past and the distant future are governed by kairotic time.

Niklas Luhmann offered an interesting insight on this topic in his systems vocabulary. Kairotic time, "the right time", is that which creates a temporal autonomy for the system. Knorr Cetina (1999: 27) pointed out that laboratories need not deal with the events when they happen: they might record them and put off tackling them until a "better time", when there are more resources, better machines, or researchers with time at their hands. Most contemporary organizations are expected to react to what happens when it happens. But, says Luhmann, "[if] a system always had to react to the environmental events that befall it the minute they happen, it would have little chance to select its mode of reacting" (1995:186). Kairotic time permits "individual" timing: "It is too early to do something about it now." If, however, organizations ran on kairotic time only, no train would ever leave on time. "Thus temporal autonomy 
creates its own problems for the system, which require their own solutions" (ibid.)

These are solutions intent on chronology: MasterPlans, Filofaxes, innumerable clocks and alarms. It is this interplay of kairotic and chronological timing that needs to be studied in organizing. Hard-technology-dependent organizing might force priority to chronological time, while organizing dependent on soft technologies might have more opportunities to create kairotic time. At present, however, organization students impose their own timing (and their own preferences) on the organizing they study. While this is a necessary ingredient of organizing a text, it needs not be done unreflectively.

\section{Dispersed calculation}

CENTER OF CALCULATION: Any site where inscriptions are combined and make possible a type of calculation. It can be a laboratory, a statistical institution, files of a geographer, a data bank and so forth. This expression locates in specific sites an ability to calculate that is too often placed in the mind. (Latour, 1999a: 304, italics added)

Equipped with this definition, I looked for an economic calculation center (or centers) in a Stockholm utility company where I had been shadowing one of the executives (Czarniawska, 2000b). Common sense guided me first to the Finance Department - which was the correct direction, but with some interesting complications. The Finance Department collected all the relevant data and calculated - but so did almost everybody else. The results of these calculations did not always tally, which provoked a new round of calculations (everywhere), but also activated non-calculative modes of negotiation.

I have therefore assumed that there was not one, but many centers of calculation. Firstly, there were several versions of the "Finance Department": the present one, and the old one that was guilty of the mistake in the long-term plan. Secondly, each department had its own finance unit that calculated the costs and produced the budgets. These calculations were actually not even made according to the same code.

Attending a budget meeting at the Department of Environment, I was struck by the lively interest of all present in understanding the economic calculations and their notso-jestful suggestions that their department could do it much better. At that point, I was still prone to see it as a matter of interdepartmental competition (our calculation 
center is better than yours!). But the following developments convinced me that there is more to it.

The Head of Environment, looking for ways to accommodate the new financial adjustments (a need for savings), decided to use the famous Swedish instrument the "cheese slicer", or rather, as she put it, a "half-cheese slicer": All were going to have to make cuts, though not equally. She went around her department and spoke to all the managers. Quite often they would have pocket calculators with them, or else turn to their computers to check the numbers. I realized that, quite apart from the Finance Department, practically everybody in management calculated and was prepared to defend her or his calculations against everybody else's. Calculation was not placed in the mind, but neither was it placed on a specific site: it was moving around.

This could be a custom specific for this utility, which was run by the engineers, ${ }^{2}$ but it differed strongly from similar units I studied in Warsaw, where engineers steered clear from the economic calculations and expressed opinions only on the outcomes, not on the procedures (Czarniawska, 2000a). What I witnessed was a clear symptom of the "audit society" (Power, 1997), where everybody has a duty - and a privilege to do economic calculations. ${ }^{3}$ An interesting case in point is that described by AnnChristine Frandsen, where a nurse empowered with a responsibility account employed a researcher as an informal consultant to support her calculations against the traditional "center" (Frandsen, 2000). Thus, although calculation centers still do exist, the activity of calculation has been dispersed in economic organizations. Multiplication of centers of calculation led to a situation where it is pointless to speak of "centers" or "specific sites". No doubt the intense education of "calculating actors" (Callon, 1998) supports this process, although not exactly in the sense intended by neoclassical economics. They might be calculating their own gains and losses or not, but it is their duty to take an active part in the collective calculation process.

How well prepared are organization students to capture these modes of organizing in the contemporary economy?

\footnotetext{
${ }^{2}$ For a comparison of the approaches of engineers and economists to the issue of cost, see Hausman and Neufeld (1988).

${ }^{3}$ According to Power, the "audit society" was enabled and aided by three programs: the New Public Management, a shift in a regulatory style, and the rise of quality assurance (1997:42).
} 


\section{Action nets, not organizations}

What is called "organization studies" usually denotes research focused on one or more of the following study objects:

- places ("organizations"). The aim is rarely to study a place, but the result is often just that. To study "Volvo" is to study its headquarters in Gothenburg, its plant in Kalmar and perhaps its Polish extension in Wroclaw. This move is dictated by the common sense of fieldwork: practices are situated, and so are their students. One has to be somewhere in order to study something. An unintended consequence is, however, an ontologization of an epistemology. Ways of doing things become places and objects; this is best seen in the example of "levels of analysis", where "micro" and "macro" seem to be two different planets "influencing" one another. The same fate met "cases": far from being "cases of something" (a phenomenon, a process), they are given proper names and become "a case of Volvo". The point is not, however, that of methodological purity, but of missing what is important in practice: contemporary organizing moves quickly from one place to another and happens in several places at once. I will return to this point in the last section of this paper.

- people (individuals or groups). Studying individual persons and their life worlds is a very appropriate task for psychologists, in the same way as studying the anatomy of interactions is the task of ethnomethodologists. Students of organizing should be fortified by this kind of knowledge, but cannot limit themselves to it. "Floor taking" and "repair" happen in all conversations, but not all conversations constitute organizing practices.

- issues. Such focus promises a better grasp on the practice of organizing, but contains a difficulty: issues as defined by whom? and at what time? One of the central aspects of organizing consists in defining and redefining the issues at stake, so that they undergo a constant process of transformation. Such transformation, however, does not follow anybody's will, and does not happen by itself: it involves multiple acts of translation, often contradictory, which are in themselves of great interest for organization scholars.

- events. This is perhaps the most promising study focus as it combines the perception of the researcher with that of the actors in the field: something has happened, and yet it is not necessary to immediately decide what it was. The 
difficulty here is that, in order to grasp the practice of organizing, it is not enough to study single events. The whole point is to know how they are related to other events, to study chains of events. Again, events do not chain spontaneously: the actors or the observers tie them to one another, usually in the activity of story making.

Karl Weick's introduction of the term "organizing" (1979) was a leap towards an avoidance of the "organizations"-trap. The difficulty in espousing his postulate in practice lies in the fact that, when studying "organizing", researchers mostly encounter processes that already came to a happy-end of a kind; that is, they became reified into "organizations". Nevertheless, to study "organizing" is to point out that "organizations" are but temporary reifications, as organizing never ceases; to study "organizations" is to deny this fact. An "action net" is a compromise devised to embrace both the anti-essentialist aspect of all organizing (organizing never stops) and its apparently solid effects (for a moment things seem unchangeable and “organized-for-good”).

The concept of "action nets" originates in a combination of new institutional theory and the sociology of translation, but is tailored specifically for organization studies (Czarniawska, 1997). It is founded on the idea that in each time and place it is possible to speak of an "institutional order", a set (not a system) of institutions (not necessarily coherent) prevalent right then and there. Such institutions shape organizing inasmuch as they dictate which actions, conventionally, should be tied together. In our present institutional order, the one who produces is supposed to try to sell her/his products, the one with money, to save or invest it. The concept of "action net" has no analytical properties; on the contrary, it tries to minimize that which is taken for granted prior to the analysis. A standard analysis begins with "actors" or "organizations": an "action net" approach permits noticing that these are products, rather than sources of the organizing - taking place within, enabled by, and constitutive of, an action net. Identities are produced by and in an action net, not vice versa.

"Organizations" become actors due to a repeated type of action legitimized by a "legal person" certificate. If we take a closer look at them, we might consider it opportune to go back to the classical definition of Perrow (1986): organizations are tools, they are machines, most closely resembling robots. An organization is a 
combination of a dispatcher (Latour, 1998a) and a translator, a machine that is given a legal personality, thus acquiring the right to an identity, a will, an image. Humans are not "cogs" in this machine anymore than they are chips in their computers (although a poetically minded writer might choose to metaphorize them so); they constructed this machine but, once constructed, the machine continues to construct them. The two main parts, a dispatcher and a translator, are dependent on one another. To be able to send objects and humans to the right places at the right time, the dispatcher must know how to contact them; the dispatcher depends on translator services. The translator is needed because there is a movement of people and objects: had they stayed at the same place, there would be no need for translation, as (supposedly) there was in the case in the tower of Babel before its fall.

What is the relation of the notion of "action nets" to concepts such as "organizational field", "network", or "Actor-Network"? Let me start with "organizational field".

When DiMaggio and Powell (1991) compared the "old" institutionalism (Selznick, 1949) to the "new" one, they pointed out that when Selznick talked about "an interorganizational field" he included all actual interactions which the TVA had with other organizations. DiMaggio and Powell's concept, borrowed from Bourdieu, has become slightly more symbolic, almost virtual as it were, since IT plays an important part in contemporary organization fields. The new institutionalists no longer talk about organizations actually interacting, but about their participating in a kind of network dealing directly or indirectly (as, for instance, consultants) with the same type of activities. The different actors need not know one another or meet, but may serve one another as role models, competitors, dream figures.

The enterprise of DiMaggio and Powell deserves praise, as it is important to understand that organizing is accomplished with the assistance of such ideal, imaginary images. Nevertheless, they have lost that which Selznick was capable of capturing: actual interactions taking place in time and space. University buildings need cleaning, even though cleaning firms do not belong to the organization field of "higher education". Yet, a cleaning firm on strike may seriously obstruct the "real" work of the university. Such an entanglement can be captured in an "action net". There is no reason to distinguish between virtual and actual contacts there, although the fact that both exist makes the study more difficult (see the last section). 
The same thing goes for "networks", although the problem with this concept relates not to space, as in the case of an "organization field", but to time. "Network" assumes actors who make contacts, whereas "action nets" assume that connections between actions produce actors: one becomes "a publisher" because s/he publishes books, but for books to be published, there must be somebody writing them. A "writer" is somebody who writes books, not someone who has a business card with this word printed on it.

Action net is close to the concept of "actor-network", as they both originate in the sociology of translation, but it attempts to avoid the difficulties of the latter, pointed out best by its creators (see Law, 1999; Latour 1999b). Had Latour in 1987 written "Follow the actants ${ }^{4}$ " instead of "Follow the actors", much trouble could have been avoided. Also, the French version of ANT spoke of reseaus - nets, not networks. As it is, the standard interpretation of ANT is "actors and their networks". To no avail, Callon attempted to change it into an "agent-network" (Callon, 1998); now it is "agents and their network", and the actors-structures connotation is further burdened by the traces of agent-principal theory. Bruno Latour spoke only half in jest when he said that there were four things wrong with ANT - the term "actor", the term "network", the term "theory" and the hyphen (Latour, 1999b). The genial approach suggested by ANT, the way of showing how actants form networks and in consequence pose as macro-actors, became almost lost.

Not that ANT needs rescuers. My intentions are much more modest, and are limited to the demands of my field - organization theory. Action net, like ANT, proposes a major reversal in the time under study: it suggests that actions - connected by translation - might produce actors, networks, and macro actors, i.e. actor-networks. Actor-networks are, however, only one possible product of translation, and one that takes more time and effort than an action net. Callon's researchers could mobilize scallops (Callon, 1986) because much earlier an innovative translation had taken place, and a new action net had been established - if you no longer can fish for scallops, you might think of cultivating them. If this translation had gone smoothly from the start, no actor-network might have emerged.

\footnotetext{
${ }^{4}$ An actant is "that which accomplishes or undergoes an act" (Greimas and Courtés 1982). This semiological term is highly suitable for social science analysis, as it allows the same entity to be a subject or an object of an act.
} 
Action nets need therefore be observed as they are being established and reestablished, which can be done progressively, deduced speculatively, or, in Foucault's terms, studied genealogically.

An action, however, is also a term heavy with connotations, as pointed out by Latour (1998a). I understand action as a movement, or an event, to which an intention can be attributed by relating the event to the social order in which it takes place (Harré, 1982). The intentions are not a priori states, but a posteriori, interpretative attributions; indeed, it is appropriate to talk about the grammar and the rhetoric of motives, i.e. the scripts underlying such attributions (Burke 1945, 1962). Such attributions can be made about any type of an actant: a human, a machine, a tree. ${ }^{5}$ Similarly, the intentions can be taken away - disattributed - even from human actants (who then no longer act, but "behave", "react", "move instinctively" etc.). What is more, a non-human equipped with a proper grammar and vocabulary of motives can make attributions of intention (for instance, a computer evaluating claims or applications).

In my studies of city management (Czarniawska, 2002b) I have tried to follow and describe such action nets, that is, the ways (some institutionalized, some innovative) in which certain actions were connected to one another. Such action nets usually transcended any given organization. Public marketing of a city company requires connections to advertisement production, to finances, to street administration, to publicity regulation etc. Such connections can assume a variety of forms: formal contracts, hierarchical subordination, but also friendship. As actions thus connected are different, they require translation that is happening at connecting points. A given unit, with its own internal actors and artifacts, may be considered an entity unto itself in a legal sense, but many other actors and artifacts, including whole networks, are usually involved in an action net. Taking entire action nets as objects of study (constructed also by the study as such), rather than mere interorganizational contacts, unveils a more comprehensive picture of how organizations are formed, stabilized, dissolved or relocated. In other words, it is easier to study organizations as products of organizing when they are not the study object in themselves. It also improves the ability to see how actants try to stabilize "their" segments of a net in order to form powerful actor-networks (Callon, 1986). An example of the latter would be an entire

\footnotetext{
${ }^{5}$ As I see it, my argument runs along lines parallel to those taken by Callon and Law (1995).
} 
set of relationships and actants representing themselves as a single actor: "the Marketing Department", "the Green Movement" etc.

Although actants access existing action nets, thus recreating and stabilizing these connections, they must also continually form new connections. Such connections are forged during the process of translation, where words, numbers, objects and people are translated into one another. Like calculation, translation is dispersed: everybody translates, although some translations, like some calculations, have more currency than others.

As not only economics, accounting and marketing but also organization studies partake in performing the economy (Callon, 1998; Cochoy 1998), the practitioners also believe in "actors and networks" rather than action nets. An interesting example of that has been found by Tatiana Pipan, who studied the preparations for the Third Millennium of Christianity Jubilee in Rome (Pipan and Porsander 2000). City administrators decided to call a meeting that would start the preparatory work. The list of participants equaled the list of the most important institutional actors in the city and the county: nobody of importance was missing. They all arrived, and became immediately engaged in the establishment of a pecking order: who was more important and for what reason? The meeting ended in a fiasco. The organizers had second thoughts and decided that first they must make a list of actions that they thought had to be undertaken; after that, it was easy to call in people who might possibly be able to do what was seen as needed. The second meeting went very well, although in time the action plans changed, different couplings were developed, etc.

This situation can be seen as analogous to a research project: action nets must be the starting point, not the result of a study. Latour once compared ANT to a shoebox: a space to put your findings in until you know where to file them (1998b). In the same vein, I see action nets as "empty concepts", to be filled with contents until it is clear what label might be put on them. Action net is a way of looking at things, not another ontological element of social reality. Studying action nets means answering a dual question: what is being done? And how does this connect to other things that are being done in the same context? It is a way of questioning that aims at capturing the traces of the past but not permitting them to decide the future: action nets, even those strongly institutionalized, are constantly remade and renewed. Digging a hole in the street requires covering it up again, but as technologies change, many things 
can be done underground without digging a hole, hole-diggers and coverers change from public servants to private entrepreneurs so that a new action, that of public tender, becomes connected, and so on.

Traditional approaches to organization studies, intent as they are on capturing "the essence of an organization", are not best equipped for seizing this kind of processes. They need rethinking.

\section{A time and a space for which traditional ethnography is not enough}

The growing interest in cultural approaches to economy produced, in organization studies, an advancement of what at first seemed to be deviant studies, like those of Dalton (1959), Burawoy (1979), and Van Maanen (1982). Even markets can now be seen as cultures (Abolafia, 1998). Consequently, there is also much debate about how to conduct studies of organizing in an anthropological mode. There is a growing group, represented most loquaciously by S. Paul Bate (1997), who considers most organization studies "quick and dirty jobs", done on an "in and out" basis, and who urges a return to the traditional work ethnography:

On closer examination "thick description" invariably turns out to be "quick description", yet another business case study or company history, a pale reflection of the experientially rich social science envisaged by early writers like Agar. "Prolonged contact with the field" means a series of flying visits rather than a longterm stay (jet plane ethnography). Organizational anthropologists rarely take a toothbrush with them these days. A journey into the organizational bush is often little more than a safe and closely chaperoned form of anthropological tourism (Bate 1997: 1150).

I am in full sympathy with Bate's critique of organization studies on the ground of their frequent cursoriness. There exist a great many studies that reach profound conclusions about humanity on the basis of the answers given to the abstract questions in interviews, which are assumed to be the windows into the depths of reality. But this problem does not have an easy solution. Too much material might be as problematic as too little, as David Silverman points out (1993). As to the cardinal rule of ethnography, the necessity for a prolonged period of participant observation, 
it encounters four problems in research on organizing: of participation, of time, of space, and of invisibility.

In the case of organization research, participant observation means that the researcher assumes the role of an organizational member (or the other way around - an employee becomes a researcher). This was the method adopted by Melville Dalton who worked as a manager, Michael Burawoy who was a machine-tool operator, John Van Maanen who was a police trainee, Robin Leidner who was a McDonald's worker and a Combined Insurance trainee (Leidner 1993).

These examples indicate that such studies - no doubt superior to all other types - are possible to carry out either due to exceptional luck in obtaining access or because a given work place does not require specific qualifications. But even the latter requires some luck or special talents. I could try to act the role of personnel manager but with such an effort that it would effectively prevent me from observing. It would take me years to obtain the state of "detached involvement" that Bruyn (1966) declared to be the ideal state for a participant observer dropped in the midst of an alien culture. A participation in a dance differs from a participation in a top management emergency meeting. It is necessary to emphasize, however, that I use the term "participant observation" literally, which does not include the cases of direct observation (Schwartzman, 1993), i.e. a situation where the researcher is present as an observer, not as a participant, such as was the case of Gideon Kunda (1992) and Mitchel Abolafia (1996). Direct observation is an obvious possibility for organization students and it is enhanced if the time of observation is prolonged. This is not to say that the longer, the better.

The issue of time is problematic in organization studies in more than one sense (Czarniawska, 1998). Consider, for example, the advice that Sharon Traweek gave to her colleagues, science researchers, in her ironic and informative article on narrative strategies in science studies:

Our first field work should last a minimum of one year, preferably two; subsequent field trips can last as little as three months and as long as they occur at least every three or four years. The questions and theories change, but we study the same people if they survive as a community, and maybe later on we also study some of their neighbors. (Traweek, 1992, p. 438) 
My study of the management of the city of Warsaw (Czarniawska, 2000a) took me about fourteen months, four of which were directly in the field. During that time a new city council was elected, which meant that I lost half of my interlocutors. Moreover, "the neighbors" also changed as a result of an administrative reform. The point is that I was not studying a community of city managers but an action net of city management: interconnected acts of organizing.

Traweek has studied her Japanese physicists for something like 20 years and she feels that she is beginning to get the gist of their lives and activities. Suppose that I studied Warsaw management for twenty more years. It would no doubt be a fascinating study, but I wonder whether there will be much in the management of Warsaw in 2015 that is of crucial importance for understanding management of that city in 1995. Specific persons might retire or become exchanged as the result of the next political coup, but the actions which constitute management will remain; on the other hand, the actions' form and content might change drastically even if the same people remain as a result of, say, a new information technology or a new fashion in big city management. There is no essence that I might reveal in time.

"Japanese physicists" might be producing an impression of stability quite incidentally, by remaining in the same space. Time and space are irreversibly intertwined in practice, but they become separated in theory. This separation facilitates particular theoretical biases. Fabian (1983) says that anthropology counts the time of the Other in a different way than "our time". I will simplify Fabian's complex argument by mentioning two such differences: the Other's time goes slowly, and it is not coeval (the Other is perceived as living in another era). Now, time in contemporary complex organizations is condensed and it is counted at many places concurrently. It is not only coeval but also multiple.

One solution to this problem is not prolonging the fieldwork but studying the same object in different places at the same time. Such a move, however, reveals another difficulty resulting from an attempt to follow the anthropological tradition: that of dealing with space. An observer is usually situated - in one room, one corridor, one branch - although some "excursions" may happen, especially when a shadowing technique is used. Modern organizing, on the other hand, takes place in a net of fragmented, multiple contexts, through multitudes of kaleidoscopic movements. Organizing happens in many places at once, and organizers move around quickly and 
frequently. As Lars Strannegård put it aptly in the title of his fascinating study of an IT company (supported and complemented by the artwork of Maria Friberg), the people he studied were constantly "already elsewhere" (Strannegård and Friberg, 2001). Additionally, interactions often do not require a physical presence - Knorr Cetina and Bruegger (forthcoming) speak about embodied presence and response presence, where the latter might not be visible to an observer. As Barley and Kunda (2001:85) point out, traditional observation is usually inadequate to capture any kind of computer work, and they recommend a more sophisticated use of technical aids in observation.

One of the ways I tried to tackle some of these difficulties was by shadowing - a technique compiled from such disparate sources as Truman Capote (put to use in social sciences by Marianella Sclavi, 1989) and Henry Mintzberg (1979). I followed selected people in their everyday work for a period of about ten working days (I am not sure they could tolerate more). ${ }^{6}$ This allowed me to move with them, and also move from one point in an "action net" to another, as what I was after is not individual experience but a collective construction.

This technique, however, does not tackle the issues of simultaneity and invisibility, and so additional techniques must be considered. One of them is what I call observant participation (Czarniawska, 1998), a method I proposed and introduced in a study of a consumer goods management system in Poland. The study was carried out in several stages. In each stage, managers (from 10 to 25 at a time) in chosen organizations and under researchers' guidance collected systematic observations of events (thus producing chronological accounts) over a period of 18 months. It must be pointed out that it would have been impossible to insert up to 25 researchers as observers into organizations in the same branch. And were it possible, they would have had to wait some time to become acculturated enough to be able to start their observations. This would defy the aim of the research, which must be as condensed as the time of the actors' is. Nine years later, these organizations actually ceased to exist. Organizations are but framed pieces of institutionalized action nets, not groups of people and not communities, although for periods of time they might behave as such.

\footnotetext{
${ }^{6}$ Following a moving object or practice is another alternative.
} 
I still use this approach whenever I can because it has proved fruitful. It is a variation of what Spradley (1979) called an ethnographic interview, i.e. repetitive, open and extensive interviews aimed at achieving an account of organizing efforts. Another variation is what I would call narrative interviews (Czarniawska, 2002a): chronological relations of events that occurred under a specified period of time. This is a way to resolve the tension between chronological timing (required by a researcher) and kairotic timing (introduced by the interlocutor). In this way, I can get some chronological frame in my material (another shoebox), even if my interlocutors switch to kairotic timing. Thus narrative interviews come near to an everyday account, and therefore to direct observation.

Not that "direct observation" gives the researcher a key to reality that "indirect observation" (via other people's accounts) cannot give. A direct observation produces just one more account - that of the researcher. Its main advantage is that it is what Marjorie De Vault (1987) called a novel reading - an account from a person who is not socialized into the same interpretative tradition, but is familiar enough with it to recognize it as such. It may thus vary from a standard account of the same event and because of this bring in new insights - a "meaning added".

I do not claim to have found the right approach to studies of organizing. I am groping in the darkness like everybody else. The attractiveness of all approaches needs to be measured against the degree to which they permit one to tackle the peculiarities of modern organizing: the coeval and multiple time, the simultaneity of events taking place in different settings, and the invisibility of a growing part of operations. It might happen that traditional observation will be impossible in cyberspace or to the contrary - that it will be possible to the extent that no other techniques will ever be needed. Whichever is the case, I believe that studies of organizing need to invent their own "mobile ethnology": the ways of studying the ways of work of people who move fast from one place to another.

\footnotetext{
${ }^{7}$ Which is very likely. Thompson (1978) pointed out that framing life-story interviews chronologically, the researchers already impose a western, modern "life as a project" scheme. A more spontaneous way of accounting for one's life (including work life) is to plot it against a circular line: work weeks, tourist seasons, budget years are the contemporary equivalents of lunar months, solar seasons etc.
} 


\section{References}

Abolafia, Mitchell Y. (1996) Making markets: Opportunism and restraint on Wall Street. Cambridge: Harvard University Press.

Abolafia, Mitchell Y. (1998) Markets as cultures: An ethnographic approach. In Michel Callon (ed.) The laws of the markets. Oxford: Blackwell, 69-85.

Barley, Stephen R. and Kunda, Gideon (2001) Bringing work back in. Organization Science, 12(1): 76-95.

Bate, S. Paul (1997) 'Whatever happened to organizational anthropology? A review of organizational ethnography and anthropological studies.' Human Relations, 50: 11471175.

Bruyn, Severyn (1966) The human perspective in sociology. The methodology of participant observation. Englewood Cliffs, NJ: Prentice-Hall.

Burawoy, Michael (1979) Manufacturing consent. Chicago, IL: University of Chicago Press.

Burke, Kenneth (1945/1969) A grammar of motives. Berkeley, CA: The University of California Press.

Burke, Kenneth (1962/1969) A rhetoric of motives. Berkeley, CA: The University of California Press.

Callon, Michel (1986) Some elements of a sociology of translation: Domestication of the scallops and the fishermen of St Brieuc Bay. In: Law, John (ed.) Power, action and belief. London: Routledge and Kegan Paul, 196-233.

Callon, Michel (1998) Introduction: The embeddedness of economic markets in economics. In: Callon, Michel (ed.) The laws of the markets. Oxford: Blackwell, 1-57.

Callon, Michel and Law, John (1995) Agency and the hybrid collectif. The South Atlantic Quarterly, 94(2): 481-501.

Cochoy, Franck (1998) Another discipline for the market economy: marketing as performative knowledge and know-how for capitalism. In: Callon, Michel (ed.) The laws of the markets. Oxford: Blackwell, 194-221.

Czarniawska-Joerges, Barbara (1988) Ideological control in nonideological organizations. New York: Praeger.

Czarniawska, Barbara (1997) Narrating organizations. Dramas of institutional identity. Chicago: University of Chicago Press.

Czarniawska, Barbara (1998) A narrative approach in organization studies. Thousand Oaks, CA: Sage.

Czarniawska, Barbara (2000a) A city reframed. Managing Warsaw in the 1990s. Harwood: Reading, UK.

Czarniawska, Barbara (2000b) Organizational translations. In: Kalthoff, Herbert, Rottenburg, Richard and Hans-Jürgen Wagener (eds.) Facts and figures. Economic representations and practices. Marburg: Metropolis Verlag, 117-142.'

Czarniawska, Barbara (2002a) Narrative, interviews and organizations. In: Gubrium, Jaber F., and Holstein, James (eds.) Handbook of interview research. Context and Method. Thousand Oaks: Sage, 733-750. 
Czarniawska, Barbara (2002b) A tale of three cities, or the glocalization of city management. Oxford, UK: Oxford University Press.

Czarniawska, Barbara (2003) The use of the narrative in social science research. In: Bryman, Allan (ed.) Handbook of qualitative data analysis. Thousand Oaks: Sage.

Dalton, Melville (1959) Men who manage. New York: Wiley.

DeVault, Marjorie L. (1990) Novel readings: The social organization of interpretation. American Journal of Sociology, 95(4): 887-921.

DiMaggio, Paul and Powell, Walter W. (1991) (eds.) The new institutionalism in organizational analysis. Chicago, IL: University of Chicago Press.

Fabian, Johannes (1983) Time and the Other. How anthropology makes its object. New York: Columbia University Press.

Frandsen, Ann-Christine (2000) From psoriasis to a number. Paper presented at IPA conference, Manchester, July.

Greimas, Algirdas J. and Courtés, Joseph (1982) Semiotics and language. An analytical dictionary. Bloomington, IN: Indiana University Press.

Harré, Rom (1982) Theoretical preliminaries to the study of action. In: von Cranach, Mario and Harré, Rom (eds.) The analysis of action: Recent theoretical and empirical advances. Cambridge, UK: Cambridge University Press, 5-33.

Hausman, Warren H. and Neufeld, J. (1989) Engineers and economists: Historical perspectives on the pricing of electricity. Technology and Culture, 30: 83-104.

Knorr Cetina, Karin (1981) The manufacture of knowledge. An essay on constructivist and contextual nature of science. Oxford, UK: Pergamon Press.

Knorr Cetina, Karin (1999) Epistemic cultures. How the sciences make knowledge. Cambridge, MA: Harvard University Press.

Knorr Cetina, Karin and Bruegger, Urs (forthcoming) Global microstructures: The virtual societies of financial markets. American Journal of Sociology.

Kunda, Gideon (1992) Engineering culture: Control and commitment in a high-tech organization. Philadelphia: Temple University Press.

Lanham, Richard A. (1991) A handlist of rhetorical terms. Berkeley, CA: University of California Press.

Latour, Bruno and Woolgar, Steve (1979/1986) Laboratory life. The construction of scientific facts. Princeton, NJ: Princeton University Press.

Latour, Bruno (1998a) Artefaktens återkomst. Stockholm: Nerenius \& Santérus.

Latour, Bruno (1998b) Comments during the seminar "Sociology of translation in organization theory", Gothenburg, September.

Latour, Bruno (1999a) Pandora's hope. Cambridge, MA: Harvard University Press.

Latour, Bruno (1999b) On recalling ANT. In: Law, John and Hassard, John (eds.) Actor Network Theory and after. Oxford: Blackwell, 15-25.

Law, John (1994) Organizing modernity. Oxford: Blackwell.

Law, John (1999) After ANT: Complexity, naming and topology. In: Law, John and Hassard, John (eds.) Actor Network Theory and after. Oxford: Blackwell, 1-14. 
Leidner, Robin (1993) Fast food, fast talk. Service work and the routinization of everyday life. Berkeley: University of California Press.

Luhmann, Niklas (1995) Social systems. Stanford, CA: Stanford University Press.

Mandler Matter, Jean (1984) Stories, scripts and scenes: Aspects of schema theory. Hillsdale, NJ: Lawrence Erlbaum.

Mintzberg, Henry (1979) The structuring of organizations. Englewood Cliffs, NJ: Prentice Hall.

Perrow, Charles (1986) Complex organizations. New York: Random House.

Pipan, Tatiana and Porsander, Lena (2000) Imitating uniqueness: How big cities organize big events. Organization Studies, 21(0):1-28.

Power, Michael (1997) The audit society. Oxford, UK: Oxford University Press.

Schwartzman, Helen B. (1993) Ethnography in organizations. Newbury Park, CA: SAGE.

Sclavi, Marianella (1989) Ad una panna da terra. Milan: Feltrinelli.

Selznick, Philip (1949) TVA and the grass roots. Berkeley, CA: University of California Press.

Silverman, David (1993) Interpreting qualitative data. London: SAGE.

Spradley, James P. (1979) The ethnographic interview. New York: Holt, Rinehart and Winston.

Strannegård, Lars and Friberg, Maria (2001) Already elsewhere - Play, identity and speed in the business world. Stockholm: Raster.

Thompson, Paul (1978) The voice of the past. Oral history. Oxford, UK: Oxford University Press.

Traweek, Sharon (1992) Border crossings: Narrative strategies in science studies and among physicists in Tsukuba Science City, Japan. In: Andrew Pickering, (ed.) Science as practice and culture, 429-466. Chicago: The University of Chicago Press.

Van Maanen, John (1982) Fieldwork on the beat. In: John Van Maanen, J. Dabber, and R. Faulkner, (eds). Varieties of qualitative research. Beverly Hills, CA: SAGE.

Weick, Karl E. (1979) The social psychology of organizing. Reading, MA: Addison-Wesley.

White, Hayden (1987) The content of the form. Baltimore: John Hopkins University Press.

White, Hayden (2000) Historical fulfillment: Cosmos, chaos and sequence in historiological representation. A seminar at Stanford University, Department of Comparative Literature, February 24. 